\title{
Preparation and Electrocatalytic Oxidation Characteristics of Ethanol on Pd/C Catalyst
}

\author{
Ling Ai-xia ${ }^{a}$, ,Xu Zhi-qiang ${ }^{b}$,Shan Jiong-chen ${ }^{c}$, Liu Jing ${ }^{d}$ and Kong Fan-dong ${ }^{e *}$ \\ Department of Pharmacy, Jining Medical University, Rizhao China

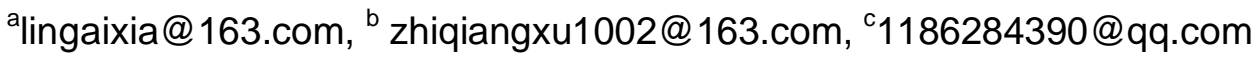 \\ d jingliuwj@163.com, ${ }^{e j y k f d @ 126 . c o m ~}$ \\ ${ }^{*}$ Corresponding author
}

Keyword: Pd/C Catalyst; Electrocatalytic Oxidation; Microwave-assisted polyol synthesis

Abstract: Nanoparticle $\mathrm{Pd} / \mathrm{C}$ catalyst was prepared by a microwave-assisted polyol process (MAPP).Ethylene glycol was used as reducing agent. The $\mathrm{Pd} / \mathrm{C}$ catalyst was characterized by transmission electron microscopy(TEM) and X-ray diffractometry(XRD). The catalyst was spherical and homogeneously dispersed on activated carbon carrier with particle size about 5-7nm. Electrochemical analysis results shows, $\mathrm{Pd} / \mathrm{C}$ catalyst exhibits higher reactivity toward electrocatalytic oxidation ethanol in alkaline electrolyte, compared to commercial Pd/C (Johnson Matthey Co.).

\section{Introduction}

Direct alcohol fuel cells (DAFCs) are very attractive nowadays ${ }^{[1-3]}$. It was considered as possible power sources for the electronic devices and electromobiles ${ }^{[4]}$. Ethanol proves to be a promising option as fuel due to its high energy density and environmental friendship ${ }^{[5]}$, and it can be easily mass-produced by the fermentation of the raw materials of sugars ${ }^{[6,7,10]}$.

The electroactivity of anodic material is one of the main factors affecting the practical use of DAFCs. Platinum electrode has high catalytic activity for the oxidation of ethanol, but the widely application of Pt electrode as anode is limited by the high cost of platinum ${ }^{[10]}$. If the DAFCs can be achieved in an alkaline medium instead of an acidic media, the kinetics of the fuel cell will be significantly improved ${ }^{[10,11]}$. According to the research report, Pd is a good electrocatalyst for ethanol oxidation and shows higher activity than that of $\mathrm{Pt}$ in alkaline medium ${ }^{[8,9]}$.

Recently, nano palladium has received a great deal of attention due to some outstanding advantages, such as significantly large surface area and high stability ${ }^{[10]}$. In this work, $\mathrm{Pd} / \mathrm{C}$ catalyst was successfully prepared by a microwave-assisted polyol process (MAPP) ${ }^{[11]}$.

\section{Experimental}

All reagents were analytical reagent grade. Palladium(II) chloride was from the Shanghai Fine Chemical Material Research Institute (China); 5\% Nafion solution was from DuPont Co. Ltd (USA); Vulcan XC-72 was purchased from Cabot Co.Ltd. (USA); the water used in the experiments was double distilled and deionized. Preparation of the XC-72carbon: XC-72carbon was placed in5M $\mathrm{HNO}_{3}$ solution with continuously stirring.

Preparation of palladium catalyst ${ }^{[11]}$ : $\mathrm{Pd} / \mathrm{C}(20 \mathrm{wt} \% \mathrm{Pd})$ catalyst was prepared through a microwave-assisted polyol process (MAPP). Briefly, $40 \mathrm{mg}$ of XC-72carbon was dispersed into a 
mixture solution of $25 \mathrm{~mL}$ ethylene glycol and $5 \mathrm{~mL}$ isopropyl alcohol under ultrasonic treatment for $2 \mathrm{~h}$. Then, amount of $\mathrm{PdCl}_{2} / \mathrm{EG}$ solution was added and continuously stirred for $2 \mathrm{~h}$. The mixture was adjusted to $\mathrm{pH}$ value of about 12.00 by adding $1 \mathrm{~mol} \mathrm{~L}{ }^{-1} \mathrm{NaOH} / \mathrm{EG}$ solution, fed with argon gas for $15 \mathrm{~min}$, then heated in a microwave reactor for $1 \mathrm{~min}$. Down to room temperature, $0.1 \mathrm{~mol}$ $\mathrm{L}^{-1} \mathrm{HNO}_{3} / \mathrm{H}_{2} \mathrm{O}$ solution was added to adjust $\mathrm{pH}$ value to $3-4$, continuously stirring for $12 \mathrm{~h}$. Finally, the mixture was filtered and washed repeatedly with ultrapure water. The product was dried in a vacuum oven for $8 \mathrm{~h}$ at $60 \stackrel{\circ}{\circ}$.

The structures of samples were characterized by a Bruker D8-Advance Powder X-ray diffractometer with $\mathrm{Cu} \mathrm{K \alpha}$ radiation $(\lambda=0.154059 \mathrm{~nm})$.TEM images were characterized with a JEM-2100FHR-TEM model using an accelerating voltage of 80 and $200 \mathrm{KV}$. All electrochemical measurements were performed using a CHI660C Electrochemical Analyzerin a standard three-electrode cell.

$5 \mathrm{mg}$ electrocatalyst sample was ultrasonic dispersion in the mixer solution which contains $1 \mathrm{~mL}$ ethanol and $120 \mu \mathrm{L} \mathrm{5 \%} \mathrm{Nafion} \mathrm{solution.} 5 \mu \mathrm{L}$ of the ink was loaded on the glassy carbon disk electrode (4 $\mathrm{mm}$ in diameter) and dried it in argon atmosphere.

Electrochemical measurements were carried out in a standard three-electrode electrochemical cell. The glassy carbon disk electrode made by above-mentioned procedure was used as the working electrode. A piece of $\mathrm{Pt}$ foil $\left(1 \mathrm{~cm}^{2}\right)$ and $\mathrm{Hg} / \mathrm{Hg}_{2} \mathrm{Cl}_{2}$ were used as the reference electrode and the counter electrode (Pt electrode), respectively.

The cyclic voltammetry (CV) tests were carried out in the $1 \mathrm{~mol} \mathrm{~L}{ }^{-1} \mathrm{NaOH}+\mathrm{C}_{2} \mathrm{H}_{5} \mathrm{OH}$ solution.After pure nitrogen gas (99.99\%) was bubbled through the solution for 30min, the experiments conducted a continuous $\mathrm{CV}$ cycling with the scan speed at $0.05 \mathrm{~V} \mathrm{~s}^{-1}$ and the potential range is from -1.0 to $0.1 \mathrm{~V}$.

\section{Results and Discussion}

Fig. 1 shows the X-ray diffraction (XRD) patterns of the $\mathrm{Pd} / \mathrm{C}(20 \% \mathrm{Pd})$ catalyst. The diffraction peaks of $\mathrm{Pd} / \mathrm{C}$ can be observed and their $2 \theta$ values of $40.11^{\circ}, 46.64^{\circ}, 68.11^{\circ}, 81.97^{\circ}$ and $86.60^{\circ}$, is corresponding to planes of (111), (200), (220), (311), and (222) respectively. This is very coincident with JCPDS No.65-6174. There are no other obvious peaks than the five peaks, indicating that the metal Pd was successfully supported on the activated carbon carrier.

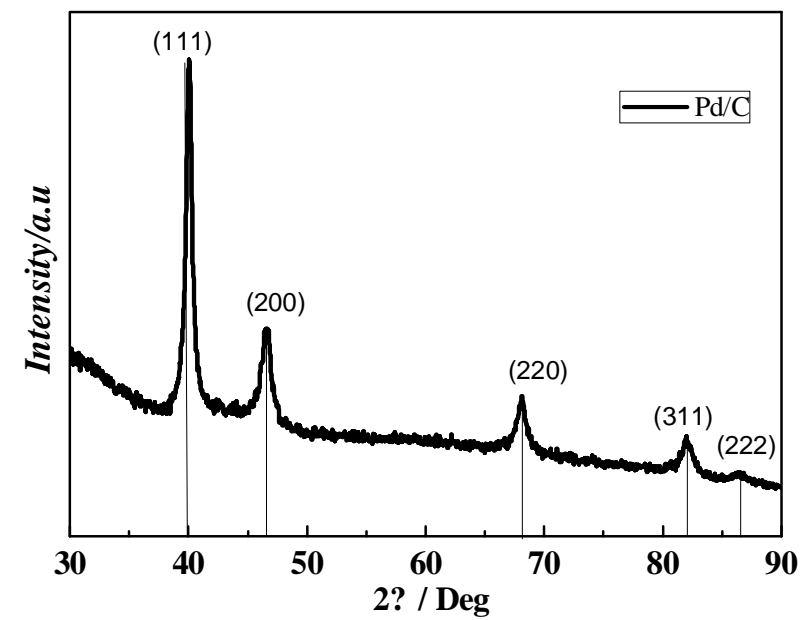

Fig.1 XRD patterns of $\mathrm{Pd} / \mathrm{C}$ catalyst

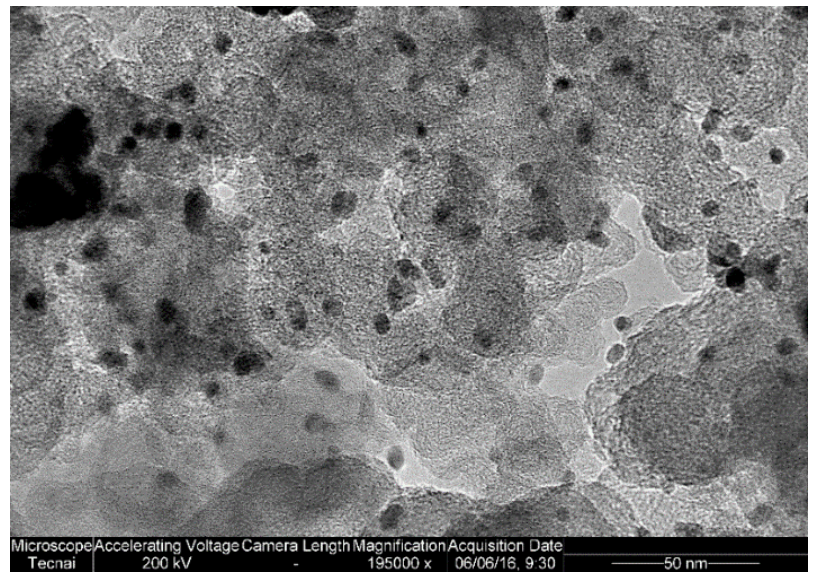

Fig. 2 TEM image of Pd /C catalyst

TEM images of $\mathrm{Pd} / \mathrm{C}(20 \% \mathrm{Pd})$ catalyst is shown in Fig.2. Pd nanoparticles with excellent uniformity and homogeneously dispersed on activated carbon carrier can be observed and the 
average particle size is around $5-7 \mathrm{~nm}$.

The cyclic voltammetric curve of $\mathrm{Pd} / \mathrm{C}$ catalysts in $1 \mathrm{~mol} \cdot \mathrm{L}^{-1} \mathrm{C}_{2} \mathrm{H}_{5} \mathrm{OH}+1 \mathrm{~mol} \cdot \mathrm{L}^{-1} \mathrm{NaOH}$ at room temperature is shown in Fig. 3. To have a fair comparison, the commercial $\mathrm{Pd} / \mathrm{C}$ catalyst (Johnson Matthey Co.) was also including this figure. The potential range is from -1.0 to $0.1 \mathrm{~V}$ and the scan rate was $50 \mathrm{mV} \cdot \mathrm{s}^{-1}$. During the forward scan there is a oxidation peak which is corresponding to the oxidation of newly chemisorbed materials coming from ethanol adsorption. At higher potentials, the formation of $\mathrm{PdO}$ retards the further adsorption of the reactive material and leads to a significant reduction in the current. During the negative scan, the as-formed PdO will be reduced to a catalytically active $\mathrm{Pd}$, this will leading to the recovery of the EOR current. From Fig. 3 it can be seen that compared with the current density on $\mathrm{Pd} / \mathrm{C}(\mathrm{J} \mathrm{M})$, the current density on $\mathrm{Pd} / \mathrm{C}$ catalyst is significant higher.The peak current densities for $\mathrm{Pd} / \mathrm{C}$ catalyst and $\mathrm{Pd} / \mathrm{C}(\mathrm{J} \mathrm{M})$ are 28.8 and 17.4 $\mathrm{mA} \cdot \mathrm{cm}^{-2}$, respectively. It shows that the $\mathrm{Pd} / \mathrm{C}$ catalyst as a better catalytic activity for $\mathrm{C}_{2} \mathrm{H}_{5} \mathrm{OH}$.

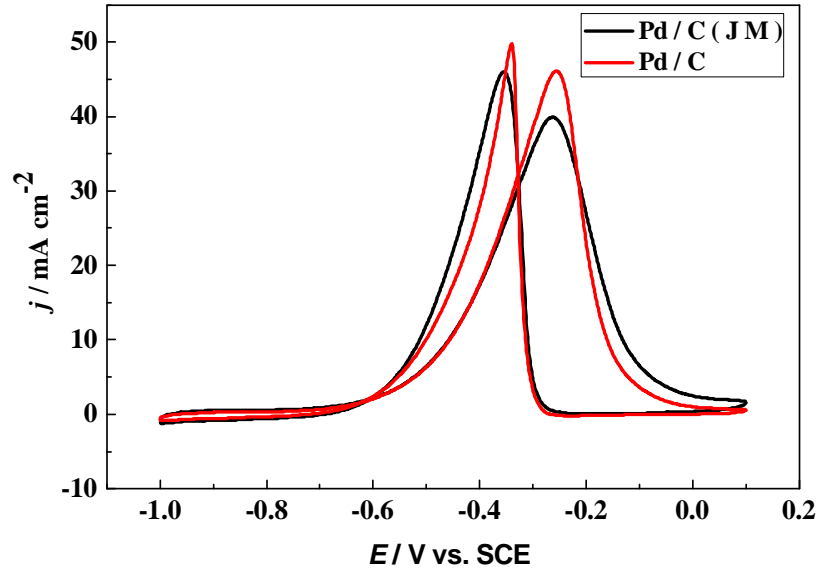

Fig. 3 Voltammetric curves of $\mathrm{Pd} / \mathrm{C}$ catalysts in $1 \mathrm{~mol} \cdot \mathrm{L}^{-1} \mathrm{C}_{2} \mathrm{H}_{5} \mathrm{OH}+1 \mathrm{~mol} \cdot \mathrm{L}^{-1} \mathrm{NaOH}$ solution

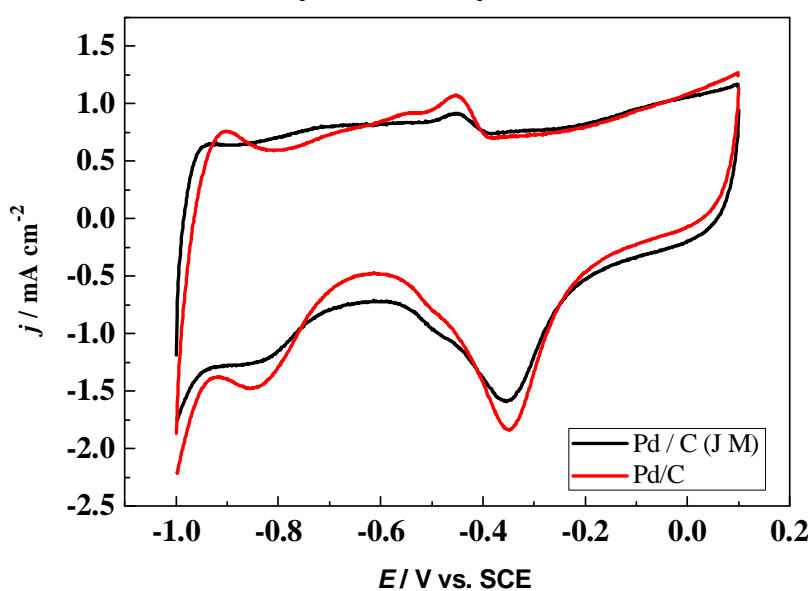

Fig. 4 Voltammetric curves of $\mathrm{Pd} / \mathrm{C}$ catalyst in $1 \mathrm{~mol} \cdot \mathrm{L}^{-1} \mathrm{NaOH}$ solution

Fig. 4 shows the cyclic voltammetry of $\mathrm{Pd} / \mathrm{C}$ catalyst and $\mathrm{Pd} / \mathrm{C}(\mathrm{JM})$ in ethanol solution in the alkaline media. It can be seen from Figure 4 that they exhibit significantly higher anode and cathode current densities. During the forward scan the oxidation peak at the lower anode potential is due to the formation of the adsorbed hydroxyl $\mathrm{OH}$ ads, which is related to the formation of $\mathrm{PdO}$ at the high positive potential. During the cathodic scan, the PdO layers are reduced and the reduction peaks is about $-0.35 \mathrm{~V}$. Obviously, $\mathrm{Pd} / \mathrm{C}$ catalyst shows a larger redox peak area than the commercial $\mathrm{Pd} / \mathrm{C}$ (JM) which indicated good electrochemical activity.

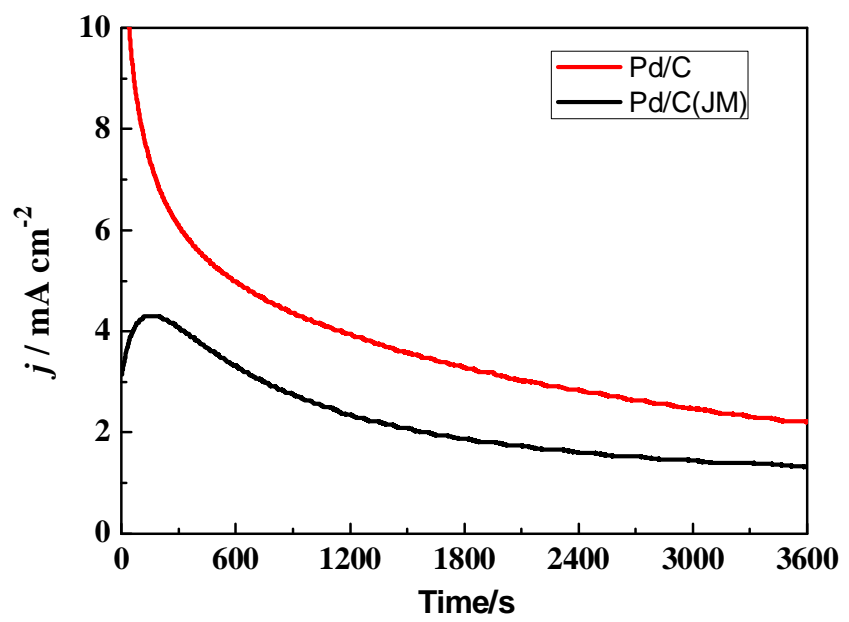

Fig.5 Chronoamperometry curves of $\mathrm{Pd} / \mathrm{C}$ catalystin $1 \mathrm{~mol} \cdot \mathrm{L}^{-1} \mathrm{C}_{2} \mathrm{H}_{5} \mathrm{OH}+1 \mathrm{~mol} \cdot \mathrm{L}^{-1} \mathrm{NaOH}$ solution Chronoamperometry measurements were conducted to evaluate the electrocatalytic stabilities of 
the catalysts in $1 \mathrm{~mol} \cdot \mathrm{L}^{-1} \mathrm{C}_{2} \mathrm{H}_{5} \mathrm{OH}+1 \mathrm{~mol} \cdot \mathrm{L}^{-1} \mathrm{NaOH}$ and the data were shown inFig.5. A lower potential $(-0.4 \mathrm{~V})$ was used to mimic catalyst deactivation. The results show that during a long duration, the current density exhibits a small attenuation at the applied constant potential.It can be seen that after3600sthe current densities on the $\mathrm{Pd} / \mathrm{C}$ catalyst and $\mathrm{Pd} / \mathrm{C}(\mathrm{J} \mathrm{M})$ are 2.3 and 1.5 $\mathrm{mA} \cdot \mathrm{cm}^{-2}$, respectively, indicating that towards $\mathrm{C}_{2} \mathrm{H}_{5} \mathrm{OH}$ oxidation in the alkaline media the $\mathrm{Pd} / \mathrm{C}$ catalyst has better stable electrocatalytic activity than commercial $\mathrm{Pd} / \mathrm{C}(\mathrm{J} \mathrm{M})$.

\section{Conclusions}

$20 \mathrm{wt} \%$ nanoparticle $\mathrm{Pd} / \mathrm{C}$ electrocatalyst was prepared by microwave-assisted polyol process. Ethylene glycol was used as reducing agent. $\mathrm{Pd} / \mathrm{C}$ catalyst have small average diameter $(5-7 \mathrm{~nm})$ and homogeneously dispersed on activated carbon carrier. Electrochemical analysis results shows, $\mathrm{Pd} / \mathrm{C}$ catalyst exhibits higher reactivity toward electrocatalytic oxidation ethanol in alkaline electrolyte, compared to commercial Pd/C (J M Co.)

\section{Acknowledgment}

This work was supported by National Undergraduate Innovation Training Program of Ministry of Education (No.201610443026), Undergraduate Innovation Training Program of Jining Medical University (No. cx2016026), Foundation of Jining Medical University (No.JY2015KJ011) and the Shandong Province Colleges and Universities Outstanding Young Teachers in Domestic Visiting Scholars Project (2014).

\section{References}

[1] T. Zhang, Q.M. Wang: J. Power Sources .Vol.140 (2005), p. 72.

[2] R. Dillon, S. Srinivasan, A.S. Arico, V. Antonucci: J. Power Sources, 127 (2004), p. 112.

[3] B.D. Lee, D.H. Jung, Y.H. Ko: J. Power Sources, Vol. 131 (2004), p. 207.

[4] Zh.L. Liu, X.H.Zhang: Electrochem. Commun.Vol. 11 (2009), p. 1667.

[5] S.C.S. Lai, M.T.M. Koper, Phys. Chem. Chem. Phys. Vol. 11 (2009), p. 10446.

[6] E. M. Cunha, J. Riberto, K. B. Kokoh: Int. J.Hydrogen Energy.Vol.36 (2011), p.11034.

[7] B.R.Tao, J.Zhang,S.C.Hui: Electrochimica Acta,Vol.55(2010), p.5019.

[8] T.Ogi,R.Honda,K.Tamaoki: Powder Technology,Vol.205 (2011), p.143.

[9] C. Mahendiran, T. Maiyalagan:Materials Chemistry and Physics. Vol.128 (2011), p. 341.

[10]L.Q.Xia, L.M. Shuang, X. Q. Jie and M.H.Min: Journal of Chemistry.Vol( 2013)1- 6

[11]F. D. Kong, S. Zhang, G. P. Yin: Catal. Lett., Vol.144,(2014), p. 242 